\title{
Effective CD4 + T-cell restoration in gut- associated lymphoid tissue of HIV-infected patients is associated with enhanced Th17 cells and polyfunctional HIV-specific T-cell responses
}

\author{
M Macal $^{1}$, S Sankaran ${ }^{1}$, T-W Chun ${ }^{2}$, E Reay ${ }^{1}$, J Flamm ${ }^{3}$, TJ Prindiville ${ }^{4}$ and S Dandekar ${ }^{1}$
}

\begin{abstract}
Human immunodeficiency virus (HIV) infection leads to severe CD4 + T-cell depletion in gut-associated lymphoid tissue (GALT) that persists despite the initiation of highly active antiretroviral therapy (HAART). It is not known whether restoration of gut mucosal CD4 + T cells and their functions is feasible during therapy and how that relates to immune correlates and viral reservoirs. Intestinal biopsies and peripheral blood samples from HIV-infected patients who were either HAART naive or on long-term HAART were evaluated. Our data demonstrated that gut CD4 + T-cell restoration ranged from modest $(<50 \%)$ to high $(>50 \%)$, compared with uninfected controls. Despite persistent CD4+ T-cell proviral burden and residual immune activation in GALT during HAART, effective CD4 + T-cell restoration ( $>50 \%$ ) was achieved, which was associated with enhanced Th17 CD4 + T-cell accumulation and polyfunctional anti-HIV cellular responses. Our findings suggest that a threshold of $>50 \%$ CD4 + T-cell restoration may be sufficient for polyfunctional HIV-specific $T$ cells with implications in the evaluation of vaccines and therapeutics.
\end{abstract}

\section{INTRODUCTION}

Highly active antiretroviral therapy (HAART) for human immunodeficiency virus (HIV) infection has advanced to provide suppression of viral replication to below detectable levels and results in the rapid restoration of $\mathrm{CD} 4+\mathrm{T}$ cells in peripheral blood. These cells, however, account for only $1-4 \%$ of lymphocytes in the body, whereas the majority of lymphocytes are found in the gut-associated lymphoid tissue (GALT). ${ }^{1}$ Although CD4+ $\mathrm{T}$-cell depletion in peripheral blood is progressive in HIV-infected patients, severe CD4 + T-cell depletion occurs rapidly in GALT during primary HIV infection. ${ }^{2-4}$

Restoration of gut CD4 + T cells is substantially delayed and incomplete compared with peripheral blood following HAART initiation. ${ }^{3-10}$ Incomplete suppression of HIV replication and persistent immune activation may contribute to the lack of gut mucosal immune restoration. ${ }^{11-13}$ It is not established whether restoration of the gut mucosal immune system and its functions is feasible during long-term HAART.
Much attention has focused on Th1 and Th2 CD4+ T-cell responses in HIV infection. Impairment of HIV-specific responses in $\mathrm{CD} 4+$ and $\mathrm{CD} 8+\mathrm{T}$-cell subsets has been detected in chronically HIV-infected patients, even during HAART ${ }^{14-17}$ and may contribute to the lack of effective clearance of HIVinfected cells. Furthermore, a newly discovered Th17 subset seems to be an important component of the gut mucosal immune defense, ${ }^{18}$ and is susceptible to simian immunodeficiency virus (SIV).${ }^{19}$ In a recent study of the SIV-infected rhesus macaque model of acquired immune deficiency syndrome, severe loss of mucosal Th17 cells was detected, which directly correlated with systemic dissemination of Salmonella typhimurium (S. typhi). ${ }^{20}$ However, information is lacking on Th17 subset depletion in GALT during chronic HIV infection and its restoration during therapy. Furthermore, it is unknown whether achieving a threshold of CD4 + T-cell restoration in GALT, despite being incomplete, might be sufficient to enhance HIV-specific polyfunctional T-cell responses.

${ }^{1}$ Department of Medical Microbiology and Immunology, University of California, Davis, California, USA. ${ }^{2}$ Laboratory of Immunoregulation, National Institute of Allergy and Infectious Disease, National Institutes of Health, Bethesda, Maryland, USA. ${ }^{3}$ Kaiser Permanente Medical Group, Sacramento, California, USA. ${ }^{4}$ Department of Internal Medicine, University of California, Davis, California, USA. Correspondence: S Dandekar (sdandekar@ucdavis.edu) 
In this study, we further investigated the impact of ongoing viral replication in GALT on CD4 + T-cell restoration and function. Despite undetectable plasma viral loads during therapy, HIV DNA and RNA are detected in GALT, ${ }^{5,21-23}$ indicating its role as a major HIV reservoir that may contribute to viral persistence. ${ }^{24-26}$ Viral persistence may contribute to chronic immune activation, considered a strong correlate of disease outcome. ${ }^{12,13}$ Our previous study demonstrated that incomplete CD4 + T-cell restoration in GALT of HIV-infected patients during HAART correlated with increased expression of immune activation-associated genes and decreased expression of mucosal regeneration-associated genes. ${ }^{5}$ Onset of disruption of the intestinal epithelial barrier and impairment of its renewal has also been detected during primary HIV infection. ${ }^{27}$ It is not well established whether the levels of viral reservoirs and immune activation in GALT may determine the varying magnitude of immune restoration during long-term therapy.

In this study, we investigated the dynamics of CD4 + T-cell restoration and its functions in GALT of HIV-infected patients during long-term HAART. We determined the magnitude of $\mathrm{CD} 4+\mathrm{T}$-cell restoration as well as the immunophenotypic and functional characterization of CD4 + T-cell subsets in the context of residual viral replication and chronic immune activation in the gut mucosa. Our findings demonstrated that, despite persistent mucosal CD4 + T-cell proviral reservoirs and immune activation, long-term HAART can lead to effective $(>50 \%)$ restoration of mucosal CD4 $+\mathrm{T}$ cells, which is associated with an accumulation of Th17 cells, polyfunctional HIV-specific cellular responses, and central memory CD4 $+\mathrm{T}$ cells. Our data suggested that a threshold of $>50 \% \mathrm{CD} 4+\mathrm{T}$-cell restoration may be sufficient to provide much needed HIV-specific immune responses in GALT.

\section{RESULTS}

\section{Clinical characteristics of patient cohorts}

Peripheral blood mononuclear cells (PBMCs) and jejunal biopsy samples were obtained from HIV-negative controls $(n=9)$ (group A) and chronically HIV-infected patients $(n=27)$, who had been seropositive for HIV antibodies for $>1$ year. Patient characteristics, clinical status, and group distribution are defined in Table 1. Group B patients were HAART naive, had detectable plasma viral loads $>50$ copies $/ \mathrm{ml}$, and CD $4+\mathrm{T}$ cells ranged from 57 to 740 cells $/ \mathrm{mm}^{3}$ in peripheral blood. Group C patients were on long-term HAART ( $>5$ years), with undetectable plasma viral loads, and peripheral blood CD $4+\mathrm{T}$ cells ranged from 279 to 1,185 cells $/ \mathrm{mm}^{3}$.

\section{Extensive CD4 + T-cell restoration in GALT of HIV-infected patients with long-term therapy}

We analyzed CD4 + T-cell subset restoration dynamics in GALT of HIV-infected patients before and during long-term therapy (Figure 1). Although therapy-naive patients (group B) exhibited severe depletion of CD4 + T cells in GALT, patients on HAART (group C) showed a modest to very high magnitude of CD4 + T-cell restoration. Six group C patients $(120,155,167$,
176, 197, and 198) demonstrated modest levels of CD4 + T-cell restoration (subgroup $\mathrm{C} 1$ ), whereas the remaining patients (subgroup $\mathrm{C} 2$ ) surprisingly had restored $\mathrm{CD} 4+\mathrm{T}$ cells to high magnitude (above 50\%) compared with uninfected controls (group A). The magnitude of gut $\mathrm{CD} 4+\mathrm{T}$-cell restoration appeared to be independent of duration of HIV-infection period or length of time on HAART and did not associate with peripheral CD4+ T-cell counts. Our data demonstrated that a substantial level of mucosal CD4 + T-cell restoration could be achieved in some patients receiving long-term HAART, suggesting that mucosal $\mathrm{CD} 4+\mathrm{T}$-cell recovery is feasible.

\section{Residual HIV replication in GALT during HAART}

To determine whether the magnitude of HIV suppression in GALT during therapy associated with CD4 + T-cell restoration levels, we measured HIV loads in plasma and intestinal biopsy samples from HIV-infected patients by real-time PCR (Figure $2 \mathbf{a}$ and $\mathbf{b}$ ). Group B demonstrated significantly higher levels of viral RNA in both plasma and GALT compared with group C. Despite undetectable plasma viral loads, several group C patients demonstrated detectable viral RNA burden in GALT. However, several subgroup $\mathrm{C} 1$ patients demonstrated higher viral RNA levels ( $>10^{3}$ copies/ $\mu$ g RNA) than subgroup C2 patients, suggesting that HIV replication suppression was critical for the restoration of CD4 + T cells in GALT. Our data indicated that long-term therapy could reduce, but not fully suppress, HIV RNA levels in the gut mucosa, although substantial gut CD4+ T-cell restoration was still possible.

\section{Persistence of HIV proviral burden in GALT despite long-term therapy}

It is not known whether HIV proviral reservoirs are reduced in the event of substantial CD4 + T-cell restoration in GALT during therapy. Therefore, we sought to determine the level of proviral burden in CD4 $+\mathrm{T}$ cells from GALT and PBMC of HIV-infected patients (Figure 2c). Proviral DNA was readily detected in CD4 + T cells isolated from groups B and C. Despite undetectable plasma viral loads and reduced jejunal viral RNA burden in group $\mathrm{C}$, the $\mathrm{CD} 4+\mathrm{T}$-cell proviral burden was similar between groups B and C. Mucosal CD4 + T cells harbored significantly higher proviral burden than those from PBMC of all HIV-infected patients $(P<0.02)$.

To determine the replication competence of the HIV provirus present in CD4 + T cells, enriched CD4 + T cells were cultured overnight, without external stimulation, and supernatants were assayed for the presence of viral RNA (Figure 2d). Group $B$ displayed the highest level of HIV RNA released from both PBMC- and GALT-derived CD4 + T cells, whereas group C had the least amount of virion release, indicating that the HIV proviral DNA in mucosal CD4 $+\mathrm{T}$ cells from these patients might not correspond to actively replicating virus and potentially represents either virus that is not replication-competent or $\mathrm{CD} 4+\mathrm{T}$-cell proviral reservoirs. This reservoir may be the result of virus seeding during primary HIV infection. Despite the presence of CD4 + T-cell proviral burden, long-term HAART led to an increased CD4 + T-cell accumulation in GALT. 
Table 1 Patient cohort and clinical characteristics

\begin{tabular}{|c|c|c|c|c|c|c|c|c|}
\hline Patient groups & $\begin{array}{l}\text { Patient } \\
\text { ID }\end{array}$ & Gender & $\begin{array}{c}\text { Age } \\
\text { (years) }\end{array}$ & $\begin{array}{c}\text { Time } \\
\text { diagnosed }\end{array}$ & $\begin{array}{l}\text { Duration } \\
\text { of HAART }\end{array}$ & HAART regimen & $\begin{array}{c}\text { CD4+ T } \\
\text { cells }\left(\mathrm{mm}^{3}\right)\end{array}$ & $\begin{array}{l}\text { Viral load (RNA } \\
\text { copies/ml) }\end{array}$ \\
\hline \multirow{8}{*}{$\begin{array}{l}\text { HIV-negative } \\
\text { controls }\end{array}$} & 151 & M & 44 & NA & $\mathrm{NA}$ & NA & 899 & NA \\
\hline & 153 & $\mathrm{~F}$ & 50 & NA & NA & NA & 406 & NA \\
\hline & 164 & $\mathrm{~F}$ & 42 & NA & NA & NA & ND & NA \\
\hline & 177 & M & 39 & NA & NA & NA & 789 & NA \\
\hline & 187 & M & 54 & NA & NA & NA & 1,271 & NA \\
\hline & 188 & M & 28 & NA & NA & NA & 620 & NA \\
\hline & 191 & $\mathrm{~F}$ & 23 & NA & NA & NA & 1,507 & NA \\
\hline & 192 & $\mathrm{~F}$ & 27 & NA & NA & NA & 1,076 & NA \\
\hline \multirow{9}{*}{$\begin{array}{l}\text { Chronic HIV } \\
\text { infection } \\
\text { HAART naive }\end{array}$} & 162 & M & 47 & 21 years & NA & NA & 266 & 2,410 \\
\hline & 165 & M & 51 & 2.5 years & NA & NA & 382 & 89,900 \\
\hline & 154 & M & 33 & $>1$ years & NA & NA & 581 & 187,000 \\
\hline & 174 & M & 37 & 6 years & NA & NA & 462 & 8,200 \\
\hline & 175 & M & 35 & 16 years & NA & NA & 537 & 24,400 \\
\hline & 152 & M & 47 & 17 years & NA & NA & 263 & 14,839 \\
\hline & 156 & M & 47 & 11 years & NA & NA & 193 & 27,023 \\
\hline & 171 & $\mathrm{~F}$ & 43 & 11 years & NA & NA & 471 & 5,190 \\
\hline & 170 & M & 45 & $>2$ years & NA & NA & 250 & 8,920 \\
\hline \multirow{13}{*}{$\begin{array}{l}\text { Chronic HIV } \\
\text { infection long- } \\
\text { term HAART }\end{array}$} & 155 & M & 38 & 7 years & 5 years & $\begin{array}{l}\text { Ritonavir/abacavir/lamivudine/ } \\
\text { Fosamprenavir }\end{array}$ & 558 & $<50$ \\
\hline & 167 & M & 47 & $>6$ years & 6 years & Tenofovir/Fosamprenavir/ritonavir & 434 & 504 \\
\hline & 176 & M & 45 & 17 years & $\begin{array}{l}>10 \\
\text { years }\end{array}$ & $\begin{array}{l}\text { Ritonavir/tenofovir/ } \\
\text { Emtricitabine/atazanavir }\end{array}$ & 758 & $<50$ \\
\hline & 197 & $\mathrm{~F}$ & 44 & $>11$ years & 11 years & $\begin{array}{l}\text { Didanosine/tenofovir/ } \\
\text { ritonavir/atazanavir }\end{array}$ & 279 & 52 \\
\hline & 198 & $\mathrm{~F}$ & 51 & 14 years & 10 years & $\begin{array}{l}\text { Tenofovir/Emtricitabine/ } \\
\text { ritonavir/atazanavir }\end{array}$ & 497 & $<50$ \\
\hline & 158 & M & 55 & 21 years & 14 years & $\begin{array}{l}\text { Abacavir/zidovudine/ } \\
\text { lamivudine/efavirenz }\end{array}$ & 873 & $<50$ \\
\hline & 166 & M & 51 & $>11$ years & 10 years & Efavirenz/tenofovir/Emtricitabine & 364 & $<50$ \\
\hline & 168 & M & 48 & 18 years & 18 years & Ritonavir/tenofovir/atazanavir & 1,185 & $<50$ \\
\hline & 169 & M & 55 & 20 years & 8 years & Efavirenz/tenofovir/AZT & 637 & $<50$ \\
\hline & 182 & M & 27 & 7 years & 5 years & Atazanavir/tenofovir/Emtricitabine & 1,040 & $<50$ \\
\hline & 189 & $\mathrm{~F}$ & 48 & $>10$ years & 8 years & Retrovir/lamivudine/efavirenz & 667 & $<50$ \\
\hline & 194 & M & 59 & 15 years & 11 years & Abacavir/lamivudine/atazanavir & 514 & $<50$ \\
\hline & 199 & $\mathrm{~F}$ & 39 & 12 years & 5 years & Idanosine/tenofovir/efavirenz & 994 & $<50$ \\
\hline
\end{tabular}

Abbreviations: HAART, Iong-term highly active antiretroviral therapy; HIV, human immunodeficiency virus; NA, not applicable; ND, not determined. 


\section{ARTICLES}

a

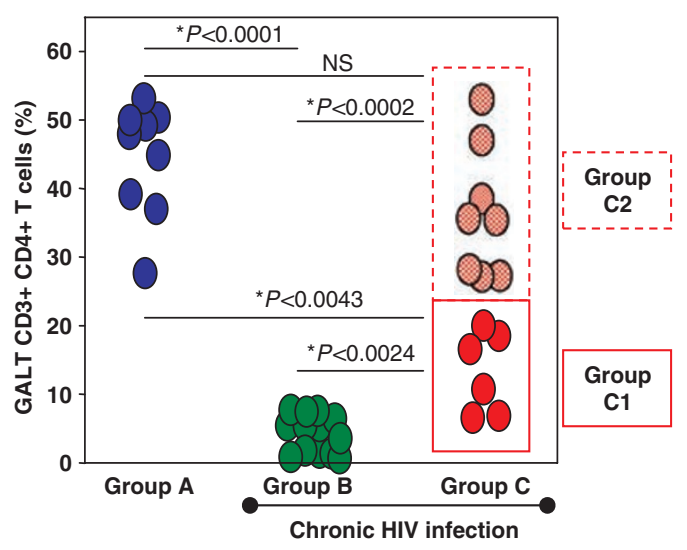

b

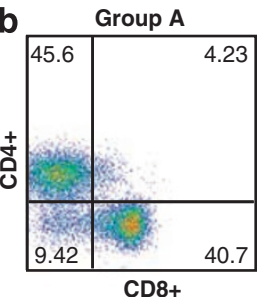

Group C1

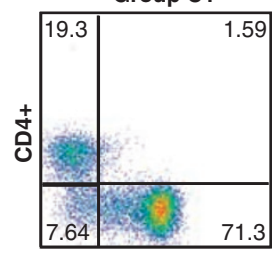

CD8+

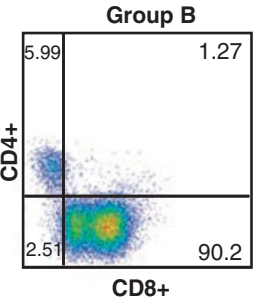

Group C2

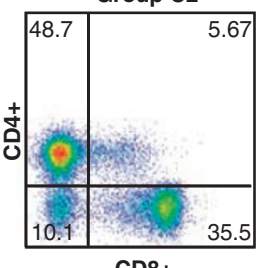

Figure 1 Varying degree of gut-associated lymphoid tissue (GALT) CD4 + T-cell restoration during highly active antiretroviral therapy (HAART). (a) GALT CD4 + T-cell percentages were determined. Patients on therapy (>5 years) were divided into two groups (boxes): those restoring CD4 + T-cell percentages above $50 \%$ (subgroup C2) and below $50 \%$ (subgroup $\mathrm{C} 1$ ) compared with baseline uninfected controls. ${ }^{*} P$-values determined by Mann-Whitney test; NS, not significant. (b) Representative flow cytometric dot plots of CD4 + T-cell restoration.
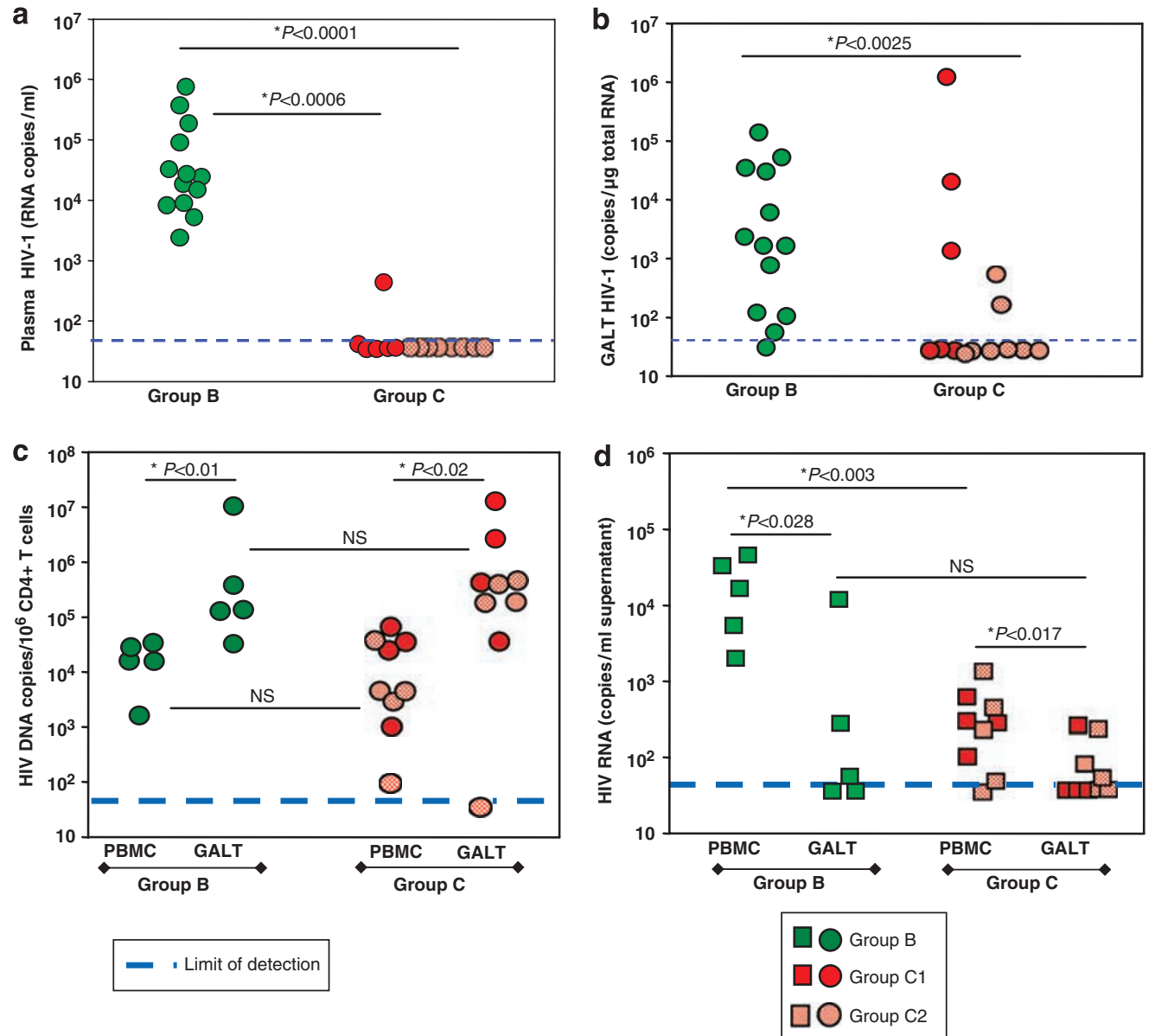

Figure 2 Reduced human immunodeficiency virus (HIV) RNA but maintained HIV provirus in gut-associated lymphoid tissue (GALT) of better restoring patients on highly active antiretroviral therapy (HAART). HIV RNA levels in (a) plasma and (b) jejunal biopsy samples were determined. (c) The level of proviral DNA copies per million enriched peripheral blood mononuclear cell (PBMC) or GALT CD4 + T cells was determined by real-time PCR.

(d) Enriched CD4 + T cells were cultured overnight and supernatant was assayed for viral RNA as a measure of cell-free viral release. The detection limit for viral RNA or DNA was 50 copies/ml plasma or supernatant or 50 copies/ $\mu$ g total RNA. ${ }^{*} P$-values determined by Mann-Whitney test; NS, not significant. 

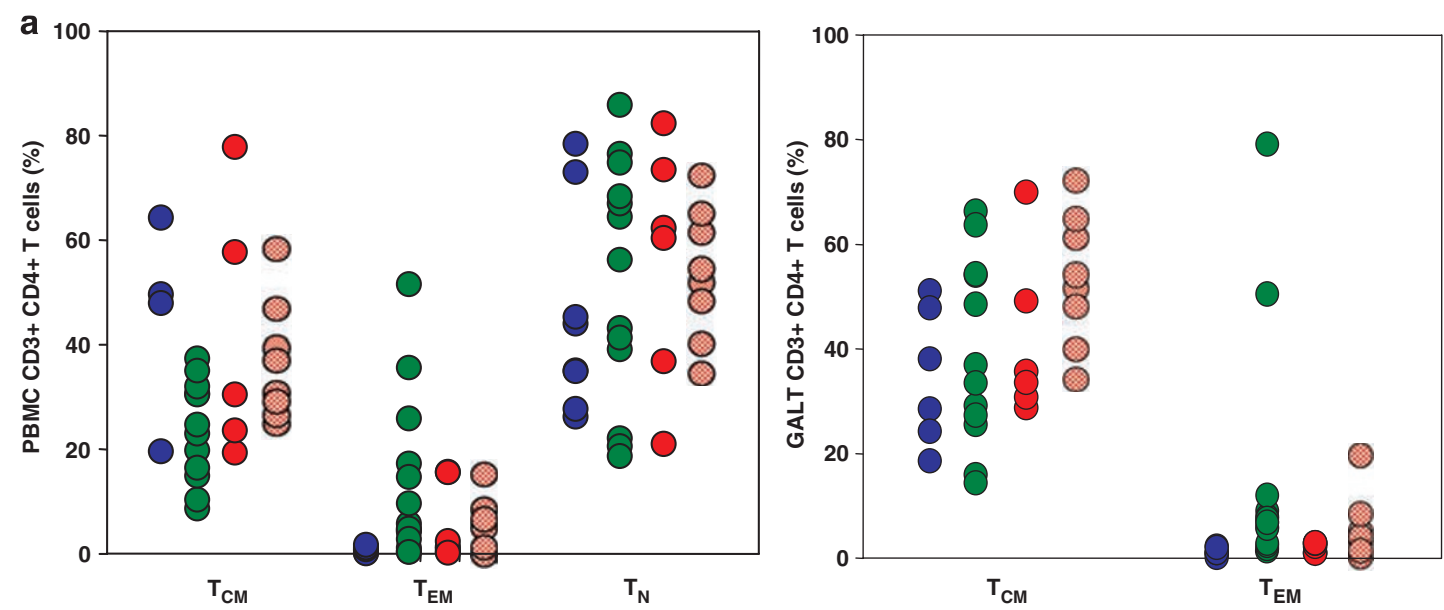

b
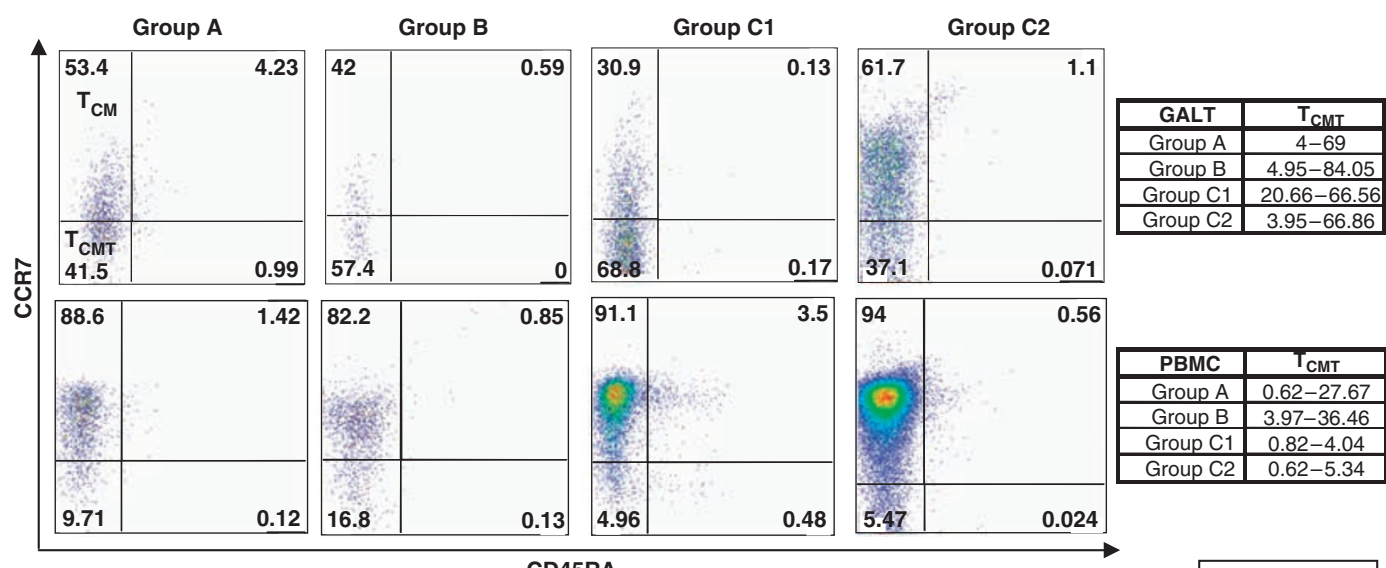

CD45RA

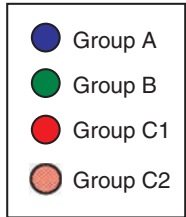

Figure 3 Increased quantity of central memory CD4+ T cells in gut-associated lymphoid tissue (GALT) of better-restoring patients. (a) Memory subset distribution in peripheral blood mononuclear cell (PBMC) and GALT CD4 + T cells was determined by multicolor flow cytometry. CD3 + CD4 + T cells were defined as effector memory $\left(T_{E M}\right): C D 45 R O+C D 95+C D 28-C D 45 R A-C C R 7-$, central memory $\left(T_{C M}\right): C D 45 R O+C D 95+C D 28+C D 45 R A-$ CCR7 + , naive $\left(T_{N}\right)$ : CD45RO-CD28 + No data were available for patients 151, 153, or 187. (b) A fourth subset was identified as transitional central memory $\left(\mathrm{T}_{\mathrm{CMT}}\right)$ : $\mathrm{CD} 45 \mathrm{RO}+\mathrm{CD} 95+\mathrm{CD} 28+\mathrm{CD} 45 \mathrm{RA}-\mathrm{CCR} 7-$. The range of CD4 + T cells with this phenotype is shown in the tables to the right.

\section{Central memory CD4 + T-cell accumulation is associated with mucosal CD4 + T-cell restoration during HAART}

To elucidate the CD4 + T-cell repertoire in GALT, we evaluated proportions of central and effector memory CD4 + T-cell subsets lost in GALT during HIV infection and the magnitude of their restoration during therapy (Figure 3). Central and effector memory subsets were defined by the expression of cell surface co-stimulatory marker CD28, the chemokine receptor CCR7, and the common leukocyte antigen splice forms CD45RO and CD45RA. ${ }^{28,29}$ We determined the presence and distribution of three memory CD4 + T-cell subsets in GALT of group A. Mucosal CD4 + T cells expressing CD45RO + CD45RA were found to be either CD95 +CD28+CCR7 + $\left(\mathrm{T}_{\mathrm{CM}}\right)$, $\mathrm{CD} 95+\mathrm{CD} 28+\mathrm{CCR} 7-\mathrm{T}_{\mathrm{CM}}$ transitional $\left(\mathrm{T}_{\mathrm{CMT}}\right)$, or $\mathrm{CD} 95+\mathrm{CD} 28-\mathrm{CCR} 7-\left(\mathrm{T}_{\mathrm{EM}}\right)$ phenotype, with a majority of the cells being either $\mathrm{T}_{\mathrm{CM}}$ or $\mathrm{T}_{\mathrm{CMT}}$.
Higher levels of mucosal CD4 $+\mathrm{T}_{\mathrm{EM}}$ were found in all HIVinfected patients compared with uninfected controls (Figure 3a). Subgroup $C 2$ demonstrated the highest level of mucosal $\mathrm{CD} 4+\mathrm{T}_{\mathrm{CM}}$, even surpassing group $\mathrm{A}_{\mathrm{CM}}$ values. Although no striking difference was observed in the distribution of mucosal CD4 + T-cell memory subsets among patient groups, the total number of $\mathrm{CD} 4+\mathrm{T}_{\mathrm{CM}}$ was highest in subgroup $\mathrm{C} 2$. Although a large proportion of CD4 + T cells in GALT are CD4 $+\mathrm{T}_{\mathrm{CMT}}$ (Figure 3b), this population is low in PBMC, rarely $>20 \%$. Our data suggested that repopulation and/or maintenance of high levels of $\mathrm{CD} 4+\mathrm{T}_{\mathrm{CM}}$ may determine the magnitude of mucosal $\mathrm{CD} 4+\mathrm{T}$-cell restoration during HAART.

To determine the early changes in CD4 + T-cell subset distribution during therapy, we performed longitudinal analysis during the first year of HAART in patients 152, 156, and 170 (Figure 4). Although the distribution of CD4+ T-cell 


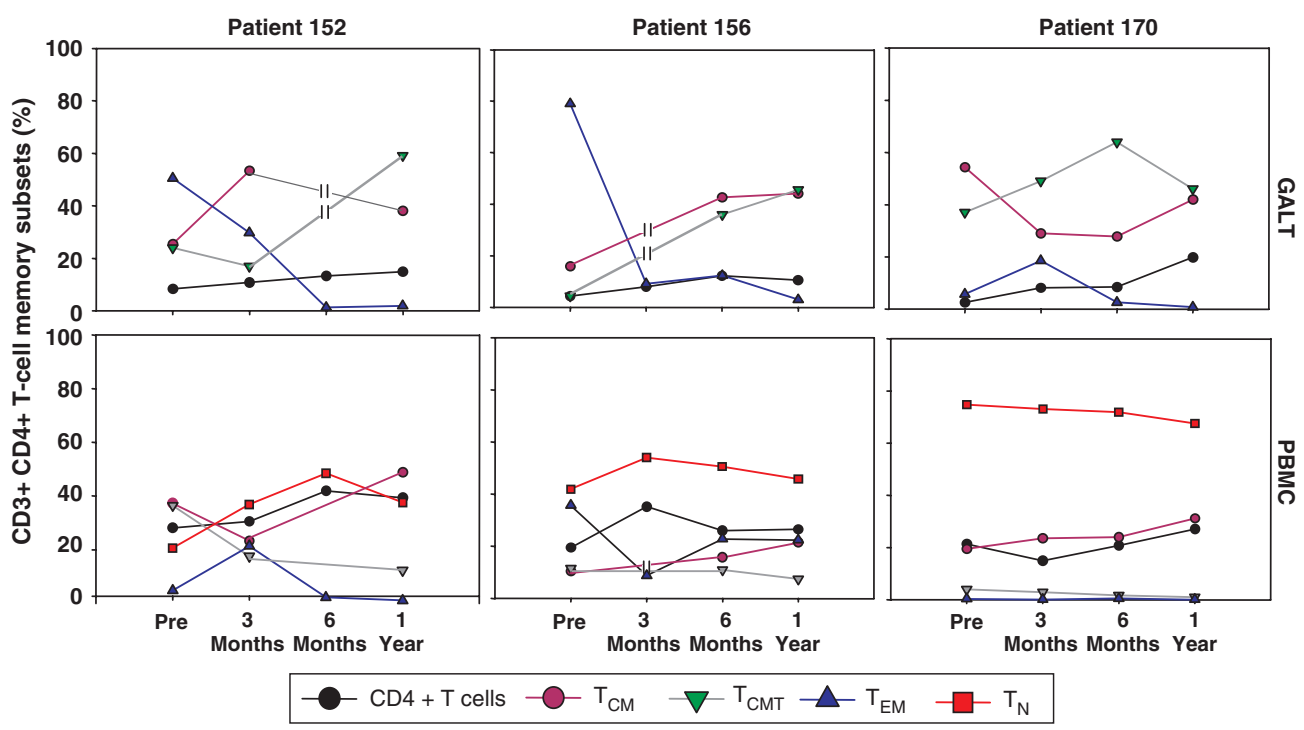

Figure 4 Longitudinal analysis of CD4 + T-cell memory subsets in patients initiating highly active antiretroviral therapy (HAART). Peripheral blood mononuclear cell (PBMC) and jejunal biopsy samples were obtained from three patients within 1 week before HAART initiation and 3 months, 6 months, and 1 year following HAART initiation. CD4 + T cells were assessed by multicolor flow cytometry for CD4 + T-cell restoration (black), $\mathrm{T}_{\mathrm{CM}}$ (purple), $\mathrm{T}_{\mathrm{CMT}}$ (green), $\mathrm{T}_{\mathrm{EM}}$ (blue), and $\mathrm{T}_{\mathrm{N}}$ (red). Parallel bars indicate time point not available.

memory subsets varied pre-HAART, all three patients demonstrated a slight increase or maintained PBMC-naive CD4+ T-cell $(\mathrm{CD} 45 \mathrm{RO}-\mathrm{CD} 28+)$ and $\mathrm{CD} 4+\mathrm{T}_{\mathrm{CM}}$ levels at 1 year post-HAART. Unlike PBMC, GALT showed reduced levels of mucosal CD4 $+\mathrm{T}_{\mathrm{EM}}$ and increased levels of CD4 $+\mathrm{T}_{\mathrm{CM}}$ and $\mathrm{CD} 4+\mathrm{T}_{\mathrm{CMT}}$. These findings suggested that changes in mucosal $\mathrm{CD} 4+\mathrm{T}$-cell memory subset distribution occur very rapidly within the first year of HAART that coincided with decreasing viral loads in GALT and peripheral blood (data not shown). This rapid transition toward a $\mathrm{T}_{\mathrm{CM}}$ phenotype may lead to an accumulation of a $\mathrm{CD} 4+\mathrm{T}_{\mathrm{CM}}$ pool that helps promote $\mathrm{CD} 4+$ T-cell restoration in GALT.

\section{Effective CD4 + T-cell restoration in GALT is associated with polyfunctional HIV-specific T-cell responses}

As the impact of varying degrees of gut $\mathrm{CD} 4+\mathrm{T}$-cell restoration on the generation of HIV-specific T-cell responses has not been well investigated, we determined the frequency and polyfunctionality of HIV-specific responses in repopulating CD4 + and CD8 + T cells. Lymphocytes from HIV-infected patients were stimulated with HIVgag peptides and analyzed for single or polyfunctional response by measuring expression of interferon$\gamma(\mathrm{IFN}-\gamma)$, interleukin (IL)-2, and tumor necrosis factor- $\alpha$ (TNF$\alpha$ ) in CD4 + and CD8 + T cells (Figures 5 and 6). Overall, all HIV-infected patients demonstrated similar frequencies (averaged) of HIV-specific responses in PBMC and GALT CD4 + T cells (Figure 6a).

Although quantitative HIV-specific frequencies in GALT were similar among patient groups, HIV-specific response quality differed in terms of polyfunctionality and composition. HIV-specific CD4 + T-cell responses in PBMC were primarily composed of single IFN- $\gamma$-producing cells in group B $(0.19 \%)$ and subgroup C2 (0.49\%) and single TNF- $\alpha$-producing cells in subgroup $\mathrm{C} 1$ (0.64\%). In contrast to PBMC, HIV-specific CD4 + T-cell responses in GALT were composed of increased levels of polyfunctional dual or triple cytokine-expressing cells. Group B HIV-specific responses consisted of single IFN- $\gamma$-producing $(0.458 \%)$ and dual TNF- $\alpha$ - and IL-2-producing CD4 + T cells $(0.52 \%)$. Similarly, subgroup C1 displayed dual IFN- $\gamma$ - and TNF- $\alpha$-producing $(0.08 \%)$ and dual TNF- $\alpha$ - and IL-2-producing CD4 + T-cell responses (0.35\%) in GALT. Triple cytokineexpressing CD4 + T cells in PBMC were predominantly detected in subgroup $\mathrm{C} 2$ and, unlike groups $\mathrm{B}$ and $\mathrm{C} 1$, were the dominant cell type in GALT $(0.66 \%)$. Our data demonstrate high CD4 + T-cell restoration in GALT is associated with the appearance of polyfunctional HIV-specific CD4 + T-cell responses in several subgroup C2 patients and may contribute to the generation of effective anti-HIV responses.

\section{Polyfunctional HIV-specific CD8 + T-cell responses}

We investigated HIV-specific CD8 + T-cell responses in the context of the magnitude of $\mathrm{CD} 4+\mathrm{T}$-cell restoration during therapy (Figure 6b). PBMC CD8 + T-cell HIV-specific cytokine response was dominated by IFN- $\gamma$ production in all patient groups. Subgroup C2 displayed the highest frequency of HIV-specific CD8 + T-cell responses (1.89\%) and single IFN- $\gamma$ producing CD8 + T cells (1.08\%) in PBMC. Subgroup C2 also displayed increased polyfunctional responses composed of dual IFN- $\gamma$ - and TNF- $\alpha$-expressing CD8 + T cells $(0.52 \%$ PBMC and $0.1 \%$ GALT) as compared with groups B and C1. Low levels of triple-function CD8 + T cells in PBMC and GALT were also detected. Our data showed an increased appearance of polyfunctional HIV-specific CD8 + T-cell responses in subgroup C2 that might be important in limiting viral infection in GALT. 


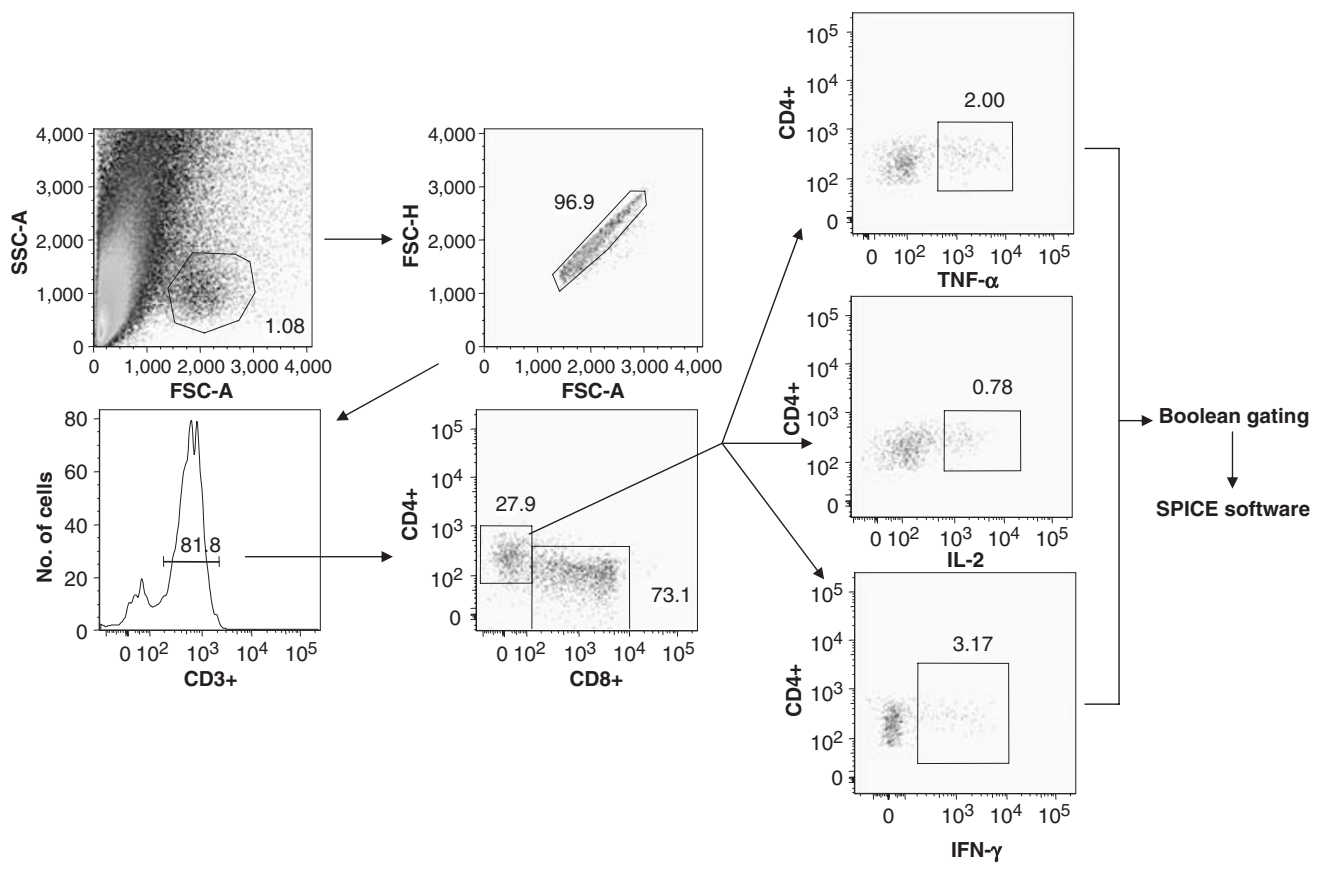

Figure 5 Multicolor flow cytometric gating strategy for human immunodeficiency virus (HIV)-specific T-cell cytokine responses. Multicolor flow cytometric gating strategy is shown for HIVgag-specific CD4 + and CD8 + T-cell 3-function response. Data depicted are from patient 166 gut CD4+ T cells stimulated with HIVgag peptides and values have been corrected for media background. Following a lymphocyte gate, cell doublet and dead cell discrimination, live cells are further gated for CD3 + T cells. CD3 + T cells are then plotted as CD4 vs. CD8. Each T-cell type is plotted against individual cytokines tumor necrosis factor- $\alpha$ (TNF- $\alpha$ ), interleukin (IL)-2, and interferon- $\gamma$ (IFN- $\gamma$ ) and positive responses are boxed. Boolean gating is performed to generate frequencies of the different combinations of function. Tables generated in Flowjo Analysis software (Tree Star) are entered into PESTLE and SPICE softwares for further qualitative analysis (Mario Roederer, NIH/VRC).

\section{Th17 CD4 + T-cell restoration in patients with elevated CD4 + T-cell restoration in GALT}

To determine whether the Th17 CD4+ T-cell subset was restored during therapy, we examined T-cell populations in PBMC and jejunal lymphocytes of HIV-infected patients compared with uninfected controls (Figure 7). Subgroup C2 had the highest levels of IL-17 + CD4 + T cells (5.4-10.4\%), far surpassing groups $\mathrm{A}(P<0.0143), \mathrm{B}(P<0.0339)$ (the value of patient 193 was omitted from statistical analysis due to severe gut $\mathrm{CD} 4+\mathrm{T}$ cell depletion and insufficient events for flow analysis that may have skewed Th17 and Th1 subset distribution), and subgroup $\mathrm{C} 1(P<0.0339)$. In contrast, decreased levels of IFN $-\gamma+\mathrm{CD} 4+$ $\mathrm{T}$ cells were observed in groups $\mathrm{B}(P<0.012)$ and $\mathrm{C} 1(P<0.014)$ when compared with group A controls, although IFN- $\gamma+\mathrm{CD} 4+$ $\mathrm{T}$-cell levels were similar among groups $\mathrm{B}$ and $\mathrm{C}$. Our findings suggest that high magnitude of CD4 + T-cell restoration in GALT was associated with accumulation and maintenance of Th17 CD4 + T cells.

\section{Persistence of immune activation in GALT despite long-term therapy}

Our previous studies ${ }^{5,27}$ found a correlation between incomplete mucosal CD4 + T-cell restoration and increased immune activation in HIV infection despite HAART. Therefore, we sought to examine whether the level of immune activation in GALT of HIVinfected patients was altered during HAART. The gene expression levels for established markers of immune activation, survival, stress, and innate inflammatory responses were measured in jejunal biopsies by real-time reverse transcription PCR. Data are presented as fold change in the gene expression levels compared with uninfected controls (Table 2). Increased expression of IFN- $\gamma$, IFN- $\alpha$, and stress markers heat-shock protein 70 and $2^{\prime}-5^{\prime}$-oligoadenylate synthetase 2 was seen in all patient groups, as well as decreased expression of IL-2 and pancreatitis-associated protein. Statistically significant differences were observed between subgroups $\mathrm{C} 1$ and $\mathrm{C} 2$ in the expression levels of TNF- $\alpha$, IL-12, IL-13, complement component C1qb, and phospholipase A2 (PLA2). Subgroup C2 had a marked increase in IL-12, IL-13, and TNF $\alpha$ and decrease in $C 1 q b$ and PLA2 genes compared with subgroup $\mathrm{C} 1$. These data showed decreased levels of inflammation in GALT during therapy in patients with enhanced CD4 + T-cell restoration. However, a low level of immune activation persisted, suggesting incomplete suppression of immune activation in GALT despite long-term therapy. This may impair or delay complete functional CD4 + T-cell restoration in GALT that is critical to eliminate or limit HIV infection in GALT.

\section{DISCUSSION}

In this study, we investigated the qualitative and functional dynamics of CD4 + T-cell restoration in GALT of HIV-infected patients during long-term HAART in the context of HIV reservoirs and immune activation in GALT. We found a substantial restoration of GALT with functional CD4 + T cells in several patients during long-term HAART, despite persistent proviral burden and low levels of immune activation. A recent study reported an incomplete CD4 + T-cell restoration in the termi- 

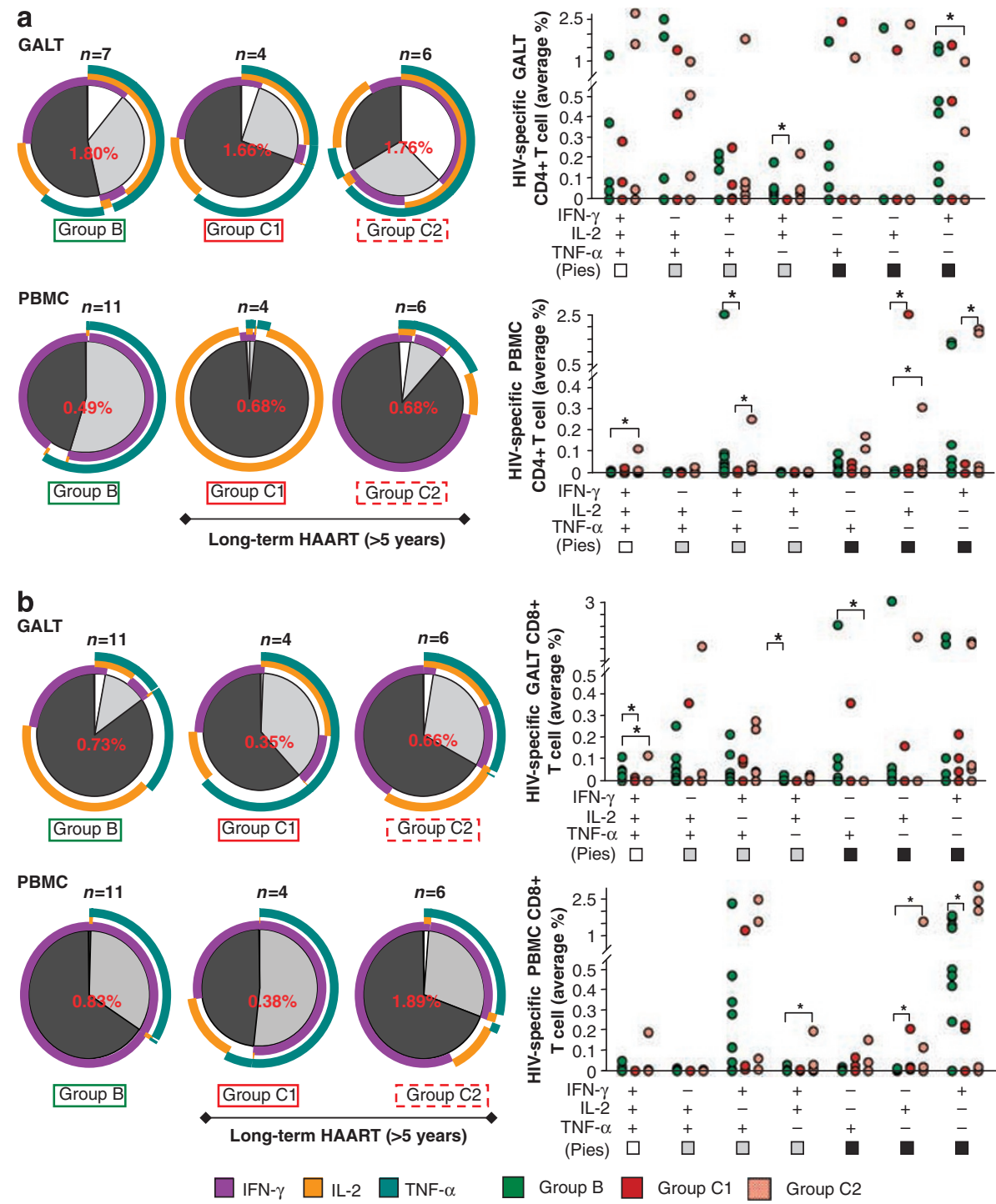

Figure 6 Improved human immunodeficiency virus (HIV)-specific T-cell responses in better-restoring patients. SPICE analysis of peripheral blood mononuclear cell (PBMC) and gut-associated lymphoid tissue (GALT) CD4 + T cell (a) and CD8 + T cell (b) HIV-specific responses are shown as mean of patient groups. Dot graphs indicate percentage of HIV-specific response based on different combinations of cytokine function. Pie charts depict qualitative distribution of HIV-specific T cells. Arcs depict cytokine makeup within pie slice. Values in center of pie charts indicate mean total frequency of T-cell HIV-specific response. Both GALT and PBMC responses were not available for patients 152, 182, 176, and 158. Patient 167 was also omitted for responses considered outliers determined by Nplot analysis in SPICE. Owing to substantially depleted GALT CD4+ T-cell percentages, CD4+ T-cell cytokine responses from highly active antiretroviral therapy (HAART)-naive patients 162, 170, 173, 175, and 193 were not included, although GALT CD8 + T-cell responses for these patients are displayed. Media values have been subtracted from HIV-specific responses. ${ }^{*} P<0.05$ determined by Mann-Whitney test.

nal ileum following long-term therapy ( $\sim 8$ years $).{ }^{23}$ We and others previously reported that gut $\mathrm{CD} 4+\mathrm{T}$-cell restoration was delayed and incomplete compared with PBMC of HIVinfected patients during the initial years of starting HAART. 3,4 Our present study shows that mucosal CD4 + T-cell restoration is feasible during HAART. Although the mechanisms of mucosal $\mathrm{CD} 4+\mathrm{T}$-cell restoration in these patients are not fully determined, it is possible that qualitative responses of these patients to therapy may be different from other patients. Our previous study reported a slower biphasic CD4 + T-cell restoration in patients initiating therapy during chronic stage of HIV infection as opposed to initiation in primary HIV infection. ${ }^{5}$ It is possible that subgroup C2 might have experienced a shorter delay in mucosal CD4 + T-cell restoration than that seen in subgroup $\mathrm{C} 1$. Reduced immune activation and better suppression of viral replication in GALT may promote the higher magnitude of CD4 + T-cell restoration in subgroup C2. This patient cohort may help further define the correlates of gut mucosal immune restoration.

Despite a high magnitude of CD4 + T-cell restoration and effective suppression of viral replication in GALT of subgroup $\mathrm{C} 2$, the $\mathrm{CD} 4+\mathrm{T}$-cell proviral burden was similar among all HIV-infected patients. Persistence of latent HIV reservoirs in $\mathrm{CD} 4+\mathrm{T}$ cells pose a major obstacle in eradication of HIV 

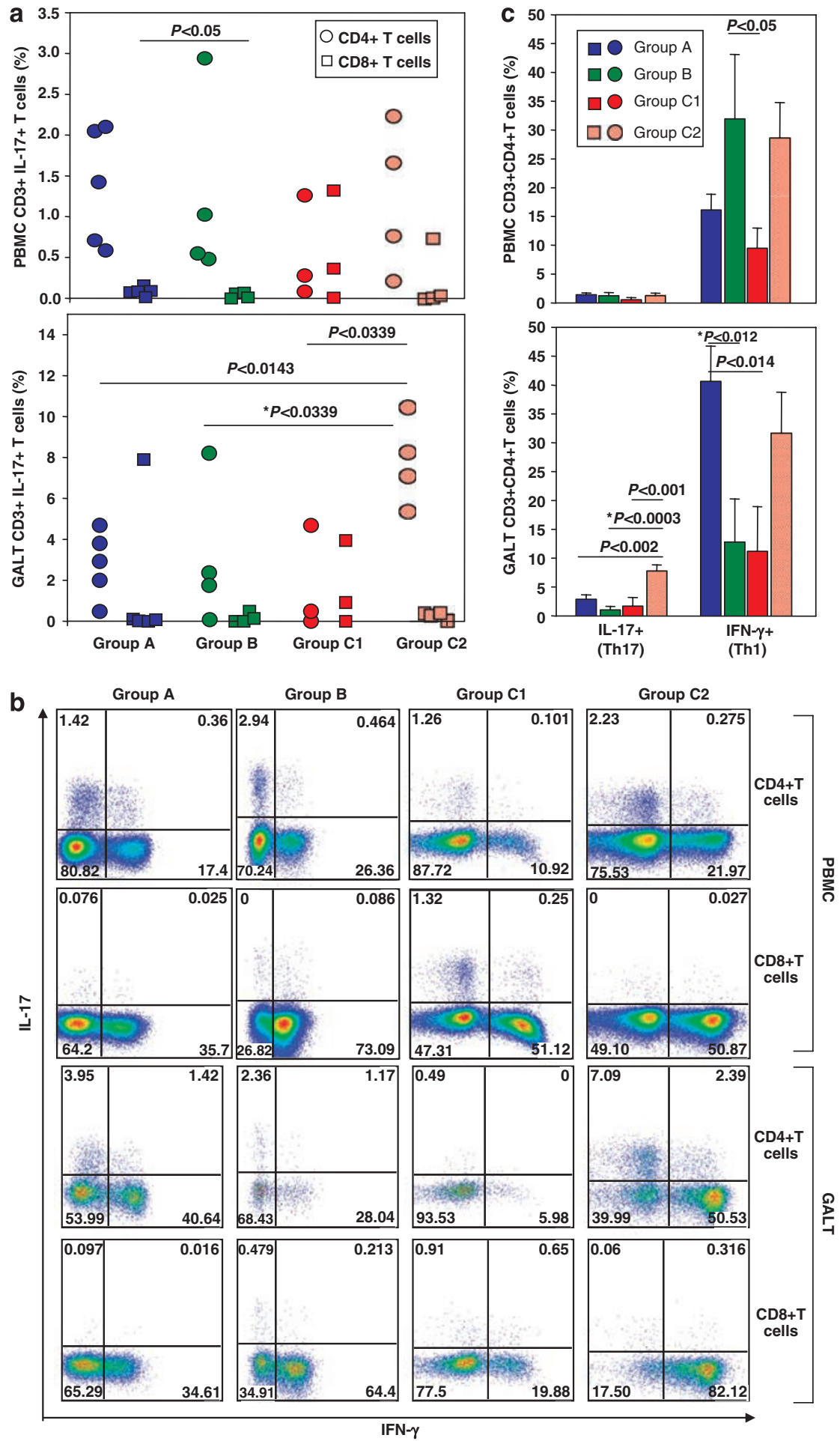

Figure 7 Long-term highly active antiretroviral therapy (HAART) can restore Th17 cells. (a) Phorbol 12-myristate 13-acetate (PMA)/ionomycin stimulation responses for IL-17-producing CD4 + (circles) and CD8 + (squares) T cells in peripheral blood mononuclear cell (PBMC) and gutassociated lymphoid tissue (GALT). P-values determined by Mann-Whitney test. (b) Representative flow cytometric dot plots of patients' PBMC and GALT PMA/ionomycin-stimulated cells. IL-17 vs. interferon- $\gamma($ IFN- $\gamma$ ) is shown. Media values have been subtracted. (c) CD4 + Th1 and Th17 percentages in PBMC and GALT following PMA/ionomycin stimulation. $P$-values determined by Student's $t$-test. ${ }^{*} P$-value excludes patient $193(8.2 \%$ CD4 + IL-17 + T cells) considered to have skewed values due to severe CD4+ T-cell depletion in GALT and few CD4+ T-cell events for flow analysis.

during therapy. ${ }^{25,26,30,31}$ Although latent CD4 + T-cell reservoirs in PBMC during therapy have been well investigated, our understanding is limited about the HIV reservoirs in GALT.
Study of distal duodenal tissue of HAART-treated patients with undetectable plasma viral loads showed persistence of HIV proviral burden. ${ }^{22}$ It is possible that there might be a continual 
Table 2 Immune activation and inflammatory gene profile

\begin{tabular}{|c|c|c|c|c|c|c|}
\hline \multirow[t]{2}{*}{ Inflammatory gene } & \multicolumn{3}{|c|}{ Mean Jejunal RNA level (relative fold change) ${ }^{a}$} & \multicolumn{3}{|c|}{$P$-values* for } \\
\hline & Group B & Group C1 & Group C2 & Group B vs. C1 & Group B vs. C2 & Group C1 vs. C2 \\
\hline \multicolumn{7}{|l|}{$T N F-\alpha$} \\
\hline s.e.m. & 0.64 & 0.34 & 0.8 & & & \\
\hline s.e.m. & 1.22 & 2.44 & 1.72 & & & \\
\hline \multicolumn{7}{|l|}{$I L-12$} \\
\hline Mean & -8.71 & -6.90 & 2.54 & NS & $<0.0024$ & $<0.0249$ \\
\hline Mean & 8.46 & 11.15 & 8.60 & NS & NS & NS \\
\hline s.e.m. & 1.88 & 8.45 & 3.34 & & & \\
\hline \multicolumn{7}{|l|}{$I L-13$} \\
\hline Mean & -1.50 & -1.50 & 7.93 & NS & $<0.0032$ & $<0.0369$ \\
\hline s.e.m. & 0.00 & 0.00 & 1.72 & & & \\
\hline \multicolumn{7}{|l|}{$I F N-\gamma$} \\
\hline Mean & 797.66 & 345.43 & 395.14 & NS & NS & NS \\
\hline \multicolumn{7}{|l|}{ Hsp70 } \\
\hline Mean & 127.53 & 74.03 & 24.38 & NS & NS & NS \\
\hline s.e.m. & 48.91 & 54.96 & 17.55 & & & \\
\hline \multicolumn{7}{|l|}{ OAS2 } \\
\hline Mean & 63.29 & 162.13 & 319.27 & NS & NS & NS \\
\hline s.e.m. & 43.17 & 129.32 & 154.92 & & & \\
\hline \multicolumn{7}{|l|}{ PLA2 } \\
\hline Mean & 1.96 & 4.30 & -2.03 & NS & $<0.0245$ & $<0.0495$ \\
\hline s.e.m. & 0.20 & 1.31 & 0.19 & & & \\
\hline \multicolumn{7}{|l|}{$P A P$} \\
\hline Mean & -4.68 & -2.40 & -7.20 & NS & NS & NS \\
\hline s.e.m. & 1.02 & 0.62 & 3.00 & & & \\
\hline
\end{tabular}

Abbreviations: Hsp, heat shock protein; IFN- $\gamma$, interferon- $\gamma$; IL, interleukin; NS, not significant; OAS, 2'-5'-oligoadenylate synthetase; PAP, pancreatitis-associated protein; PLA2, phospholipase A2; TNF- $\alpha$, tumor necrosis factor- $\alpha$.

${ }^{*} P$ values determined by Mann-Whitney test; significance considered $P<0.05$, indicated in bold.

aFold change over human immunodeficiency virus (HIV)-uninfected healthy control. 
infection occurring that might account for the maintenance of virus in GALT of patients in this study. However, residual virus may not be effectively eliminating repopulating $\mathrm{CD} 4+\mathrm{T}$ cells as we detected effective CD4 + T-cell restoration in GALT during therapy.

The maintenance of $\mathrm{CD} 4+\mathrm{T}_{\mathrm{CM}}$ cells has been correlated with protection from HIV disease, and loss of $\mathrm{T}_{\mathrm{CM}}$ has been reported during disease progression. Our evaluation of memory CD4+ T-cell subsets showed that elevated CD4 + T-cell restoration was associated with the level of $\mathrm{T}_{\mathrm{CM}}$ in GALT. Previous studies have described memory CD4 + T-cell subset distribution in PBMC during HIV infection ${ }^{16,32}$ and in GALT during SIV infection. ${ }^{7,9}$ We found that a majority of mucosal CD4 + T cells are $\mathrm{T}_{\mathrm{CM}}$ and $\mathrm{T}_{\mathrm{CMT}}$, with a minor proportion of $\mathrm{T}_{\mathrm{EM}}$ in GALT of both uninfected and HIV-infected patients on long-term HAART. Studies report a correlation between preservation of CD4 $+\mathrm{T}_{\mathrm{CM}}$ in $\mathrm{PBMC}$ and prolonged survival in vaccinated SIV-challenged rhesus macaques ${ }^{33}$ and accumulation of $\mathrm{CD} 4+\mathrm{T}_{\mathrm{CM}}$ in GALT and complete mucosal CD4 + T-cell restoration. ${ }^{34}$ Furthermore, it has been reported that low levels of HIV replication were found to maintain $\mathrm{CD} 4+\mathrm{T}_{\mathrm{CM}}$ and $\mathrm{T}_{\mathrm{EM}}$ levels. ${ }^{16,35,36}$ Our findings suggest that accumulation and maintenance of $\mathrm{CD} 4+\mathrm{T}_{\mathrm{CM}}$ in GALT during HAART provides a readily available pool of cells capable of differentiation in response to viral antigens in GALT.

We found that the magnitude of mucosal CD4 + T-cell restoration of HAART-treated patients was associated with the degree of functionality of these cells and their HIV-specific responses (Figure 6). A trend for increased HIV-specific triple cytokineproducing $\mathrm{CD} 4+\mathrm{T}$-cell responses was apparent in subgroup $\mathrm{C} 2$ compared with group B. It has been suggested that viralspecific T-cell responses may be limited in the absence of HAART, which might lead to a decreased T-cell repertoire and ineffective immune responses in HIV-infected patients. 5, 17,37,38 However, CD8 + T cells from PBMC and rectal mucosal samples of HIV-infected HAART-naive patients were shown to be able to produce at least one cytokine, indicating that full exhaustion of CD $8+\mathrm{T}$ cells had not yet occurred..$^{39}$ It has been suggested that the ability of $\mathrm{T}$ cells to produce polyfunctional cytokine responses is a better correlate of immune protection than viral loads. ${ }^{38,40}$ Our data demonstrated the presence of both a high magnitude of CD4 + T-cell restoration and also an increased appearance of polyfunctional CD4 + T cells in GALT during therapy. The reduced HIV-specific response in PBMC of all patient groups may indicate that these cells might have trafficked to GALT. Although the plasma viral loads were below detection limits, GALT in some patients had detectable levels of HIV RNA, indicating residual viral replication. Presence of viral antigens and residual viral replication in GALT during HAART may contribute to the homing of $\mathrm{T}$ cells from the periphery.

Furthermore, we found that there was a substantial increase in mucosal Th17 cells of patients with a high magnitude of mucosal $\mathrm{CD} 4+\mathrm{T}$-cell restoration during HAART, at higher levels than those in uninfected controls. Although the Th17 population is a minor subset of total CD4 + T cells, it appears to be important in generating mucosal immune defense against microbial pathogens in GALT. Cytokines IL-17 and IL-22, produced by
Th17 cells, have been implicated in mucosal defenses of the lung and intestine due to their ability to induce chemokines involved in the recruitment of neutrophils and dendritic cells to the site of infection, as well as to induce the expression of antimicrobial peptides. ${ }^{18,41}$ Studies on Th17 cells in the lung and intestinal mucosa have suggested that Th17 cells may function as a link between the innate and adaptive immune response and have shown that Th17 cells are important in the control and eradication of microbial pathogens at these mucosal sites. ${ }^{42}$ In HIV-infected patients with impaired immune functions, enteric opportunistic infections, associated enteropathy, and systemic microbial dissemination have been well described. ${ }^{12}$ We recently reported the loss of Th17 CD4 + T cells in GALT of SIV-infected rhesus macaques. Loss of Th17 CD4+ T-cell responses to $S$. typhi challenge in SIV-infected animals led to the lack of local containment of Salmonella and its systemic dissemination. ${ }^{20}$ Furthermore, a recent study has shown that Th17 cells are susceptible to SIV infection, resulting in their reduced frequencies within weeks of infection. ${ }^{19}$ Loss of Th17 cells but maintenance of Th1 cells in GALT, as we found in our study, may prolong an inflammatory condition that is characteristic of HIV and SIV infection. Our finding that subgroup C2 had the highest frequency of Th17 cells further suggested the importance of Th17 cells in the restoration of mucosal immune defenses and the regeneration of a functional gut microenvironment.

Detection of polyfunctional anti-HIV T-cell responses and suppression of viral replication in GALT and PBMC in subgroup C2 suggest that beneficial effects of CD4 + T-cell restoration can be realized even before reaching complete baseline CD4 + T-cell levels. A recent study reported that initiation of HAART during acute stage of HIV infection resulted in incomplete CD4 + T-cell restoration, even after 7 years of therapy. ${ }^{4}$ Interestingly, the CD4 + T-cell reconstitution in GALT of some of these patients reached about $50 \%$ compared with uninfected controls. Although our patient cohort is not extensive, our data strongly suggest a trend that reaching a threshold of $\mathrm{CD} 4+\mathrm{T}$-cell restoration in GALT during therapy may be sufficient to generate or maintain effective immune responses against HIV and incoming bacterial infections. This is evidenced by the appearance of enhanced polyfunctional anti-HIV responses and accumulation of Th17 cells in GALT of subgroup C2, leading to a more robust gut microenvironment that supports CD4+ T-cell restoration.

Increased expression of immune activation-related genes persisted in GALT of all patients, although to a lesser degree in subgroup C2 where viral replication was highly suppressed. Increased RNA levels of TNF- $\alpha$ and IL-13 were observed in subgroup C2 that may contribute to homeostatic processes and support the control of viral replication as suggested by previous studies. ${ }^{43-45}$ However, the persistent immune activation in GALT suggests that regulatory mechanisms of immune activation might not be fully restored. It is possible that HIV induces immune dysregulation early in infection that may impair mechanisms to regulate immune activation in GALT. This defect may persist despite the suppression of viral loads in GALT and may lead to chronic immune activation in HIV infection. Nonetheless, decreased immune activation was sufficient 
to support gut CD4 + T-cell restoration in subgroup C2. GALT samples from these patients provide an excellent opportunity to further investigate the key regulators of immune activation in GALT, potentially leading to novel therapeutic interventions.

Our findings suggest, therefore, that a high magnitude of $\mathrm{CD} 4+\mathrm{T}$-cell restoration in GALT during long-term HAART was possible despite persistent proviral burden and immune activation in HIV-infected patients. Our study also suggests that accumulation of CD4 + T cells in GALT might be a better predictor of the efficacy of therapy as it was associated with improved HIV-specific and antimicrobial CD4 + T-cell function and viral suppression in GALT. Our study highlights the importance of developing therapeutic strategies for controlling immune activation and reducing proviral burden, whereas capitalizing on the CD4 $+\mathrm{T}$ cell orchestrated immune defenses at the mucosal surfaces.

\section{METHODS}

Human subjects and sample collection. Chronically, HIV-1-infected patients $(n=27)$ were divided into cohorts including HAART naive $(n=13)$ (group B) and long-term HAART $(n=14)$ (group C), and peripheral blood samples and jejunal biopsies were obtained. HIV1 -negative individuals $(n=9)$ (group A) were enrolled in the study to provide baseline values. Jejunal biopsies were collected by upper endoscopy, under sedation. Studies were performed under informed consent and an institutional review board approved protocol.

Isolation of intestinal lymphocytes. Jejunum biopsies were placed in isolation media (RPMI-1640 supplemented with 10\% fetal bovine serum (FBS), $100 \mathrm{U} \mathrm{ml}^{-1}$ penicillin, $100 \mathrm{U} \mathrm{ml}^{-1}$ streptomycin (Gibco, Grand Island, NY), and collagenase type IIb $\left(1 \mathrm{mg} \mathrm{ml}^{-1}\right)$ (Sigma, St Louis, MO) and subjected to shaking at $37^{\circ} \mathrm{C}$ for four periods of $30 \mathrm{~min} .{ }^{3}$ Cells were then rested overnight in culture media (RPMI-1640 supplemented with $15 \% \mathrm{FBS}, 1 \%$ gentamycin, $100 \mathrm{U} \mathrm{ml}^{-1}$ penicillin, $100 \mathrm{U} \mathrm{ml}^{-1}$ streptomycin, $1 \%$ L-glutamine, $1 \%$ sodium pyruvate, $2.5 \%$ Hepes, and $0.5 \%$ amphotericin B (Gibco)) at $37{ }^{\circ} \mathrm{C}$ with $5 \% \mathrm{CO}_{2}$. Cells were passed through a $40 \mu \mathrm{m}$ filter the next day. A total of 3-4 million lymphocytes were filtered the same day for CD4 + T-cell isolation.

Isolation of PBMCs. Whole blood was collected in ethylenediaminetetraacetic acid-containing tubes and processed as described previously. ${ }^{3}$ Briefly, the white blood cell buffy coat was collected and diluted in $1 \times$ phosphate buffered saline, layered over ficoll gradients (Atlanta Biological, Lawrenceville, GA), and centrifuged. The mononuclear cell layer was collected and pelleted by centrifugation. Cells were cultured overnight at $37^{\circ} \mathrm{C}, 5 \% \mathrm{CO}_{2}$ in culture media (RPMI- 1640 supplemented with $10 \% \mathrm{FBS}, 100 \mathrm{U} \mathrm{ml}^{-1}$ penicillin/streptomycin, and $1 \% \mathrm{~L}$-glutamine (Gibco)). A total of 5-7 million PBMCs were taken same day for CD4+ T-cell isolation.

CD4 + T-cell isolation. Isolated PBMCs and jejunal lymphocytes were enriched for CD $4+$ T cells by magnetic bead sort (Dynal, Carlsbad, CA). Magnetic beads precoated with CD8 antibody were incubated with lymphocytes for $30 \mathrm{~min} / 4{ }^{\circ} \mathrm{C}$ on a rotating platform. CD8 - lymphocytes were collected by magnet and incubated with CD13-coated magnetic beads. Pan-mouse IgG beads (Dynal) were first incubated for $30 \mathrm{~min} /$ $4{ }^{\circ} \mathrm{C}$ on a rotating platform with monoclonal IgG CD13 antibody (BD, San Jose, CA) and then CD13-coated beads were incubated with CD8depleted lymphocytes for $30 \mathrm{~min} / 4{ }^{\circ} \mathrm{C}$ on a rotating platform. CD8 CD13 - lymphocytes were collected by magnet, washed in culture media, and incubated overnight at $37^{\circ} \mathrm{C} / 5 \% \mathrm{CO}_{2}$ at a maximum concentration of two million cells $/ \mathrm{ml}$. Cells were pelleted the following day and stored at $-80{ }^{\circ} \mathrm{C}$ until use. Supernatant from overnight culture was also stored at $-80{ }^{\circ} \mathrm{C}$ until needed. Purity of PBMC (90-100\%) and jejunal lymphocytes (45-85\%) was determined by flow cytometry.

Immunophenotypic analysis. Isolated lymphocytes (one million cells per tube) were incubated with Aqua Live/Dead Dye (Invitrogen, Carlsbad, CA), washed with staining buffer (filter sterilized $1 \times$ PBS with $3 \%$ heat-inactivated FBS and $0.1 \%$ sodium azide), and incubated with purified IgG2a CCR7 (R\&D systems, Minneapolis, MN) and Fcblocking reagent (Miltenyi, Auburn, CA) followed by anti-IgG2a-biotin (E-Bioscience, San Diego, CA). Cells were incubated with 10\% normal mouse serum (Jackson Immunoresearch Laboratories, West Grove, PA) followed by fluorescent mouse antihuman monoclonal antibodies CD3 APCCy7 (Beckton Dickinson, Mountain View, CA), CD45RA PECy5.5, CD45RO APC, CD8 APCCy5.5 (Invitrogen), CD95 PECy5 (Biolegend, San Diego, CA), CD28 Alexa488, CD4 Pacific Blue (E-Bioscience). Cells were incubated with streptavidin-Qdot 605 (Invitrogen) and fixed with $1 \%$ paraformaldehyde (PFA) (Sigma) before analysis on the LSR II flow cytometer (Beckton Dickinson at the UC Davis core facility). A minimum of 500,000 events were collected per sample and data were analyzed using Flow Jo (Tree Star, San Carlos, CA). Central memory CD3 + CD4 + T cells were defined as CD45RO + CD45RA - CCR7 + CD95 + CD28 + , central memory transitional CD3 $+\mathrm{CD} 4+\mathrm{T}$ cells were defined as $\mathrm{CD} 45 \mathrm{RO}+\mathrm{C}$ D45RA - CCR7 - CD95 + CD28 + , and effector memory CD3 + CD4+ T cells were defined as CD45RO + CD45RA - CCR7 - CD95 + CD28 - .

Antigen-specific assay. Isolated lymphocytes ( $\sim 1$ million cells) were stimulated with HIV-1 gag peptides (JPT Technologies, Berlin, Germany), positive control staphylococcal enterotoxin B or phorbol 12-myristate 13 -acetate $\left(1 \mathrm{ng} \mathrm{ml}^{-1}\right)+$ ionomycin $\left(1 \mu \mathrm{M} \mathrm{ml}^{-1}\right)$ (Sigma), or negative control media alone at $37^{\circ} \mathrm{C}$ with $5 \% \mathrm{CO}_{2}$ for 6 -h. Anti-CD28 pure monoclonal antibody (E-bioscience) was added to aid costimulation, followed by addition of Brefeldin A (Sigma) for the final $5 \mathrm{~h}$ to prevent Golgi transport of cytokines out of cells. Cells were washed with $1 \times$ phosphate buffered saline/1\% BSA, stained for surface markers, and fixed in 1\% PFA. Fixative was washed out and cells were permeabilized with Caltag Permeabilization Solution B (Invitrogen) and stained with monoclonal antibodies IFN- $\gamma$, IL-2, and TNF- $\alpha$ (BD, E-bioscience) for $20 \mathrm{~min}$ at room temperature. Samples were washed and fixed with $1 \%$ PFA before analysis with LSR II. A minimum of 500,000 events were collected for each sample whenever possible and analyzed using Flow Jo software. Polyfunctional analysis was performed using SPICE (v4.1.6) and PESTLE (v1.5.4) software courtesy of Mario Roederer, Vaccine Research Center, NIAID/NIH, Bethesda, MD.

Viral genomic DNA quantification. Using a minimum of 150,000enriched CD $4+\mathrm{T}$ cells, cells were lysed in $10 \mathrm{~mm}$ Tris- $\mathrm{HCl} \mathrm{pH} 8$ containing $100 \mu \mathrm{g} \mathrm{ml}^{-1}$ proteinase $\mathrm{K}$ (Roche Applied Science, Indianapolis, IN) for $1 \mathrm{~h}$ at $56^{\circ} \mathrm{C}$ followed by heat inactivation of enzyme. Real-time PCR specific for human $\beta$-actin DNA (Applied Biosystems, Foster City, CA) was performed on cell lysates to determine the exact copy number of cells per $\mu$ l of cell lysate. The amplification reaction was performed in triplicate using $0.5 \mu \mathrm{M}$ primers, $0.2 \mu \mathrm{M}$ fluorescent probe, $0.8 \mathrm{~mm}$ dNTPs, $5 \mathrm{mM} \mathrm{MgCl}_{2}$, and 2.5-U platinum taq polymerase (Invitrogen) in $50 \mu \mathrm{l}$ total volume. The following primers were used for detection of HIV DNA: 5' -GGTCTCTCTGGTTAGACCAGAT-3' (5' primer) and 5'-CTGCTAGAGATTTTCCACACTG-3' (3' primer) along with the fluorescent probe 5' -6FAM-AGTAGTGTGTGCCCGTCTGTT-TAMRA-3'. PCR conditions consisted of a denaturation step at $95^{\circ} \mathrm{C}$ for $3 \mathrm{~min}$ followed by 45 cycles of $15 \mathrm{~s}$ at $95^{\circ} \mathrm{C}$ and $1 \mathrm{~min}$ at $59^{\circ} \mathrm{C}$. Serially diluted $\mathrm{ACH}-2$ cell lysates and DNA (NIH, Bethesda, MD) were subjected to the above PCR to obtain standard curves.

Cell-free HIV quantification. Supernatants of isolated CD4 + T cells were used to determine the amount of spontaneous HIV infectious virion release. ${ }^{26}$ Supernatants were collected from the overnight cultures of 
isolated cells described, in the absence of stimuli that would activate cells. Cell-free HIV was quantified using the Amplicor HIV-1 Monitor Test (Version 1.5, detection limit 50 copies/ml; Roche Diagnostics, Indianapolis, IN) according to the manufacturer's instructions.

Viral RNA and gene expression analysis. Viral RNA copies/ml plasma was determined by Amplicor HIV-1 Monitor Test. Total RNA, extracted from jejunal biopsies, was processed as previously published. ${ }^{27} \mathrm{cDNA}$ was used in real-time TaqMan PCR assay and RNA copy numbers were extrapolated from a previously constructed standard curve. Host gene expression was assayed using real-time TaqMan PCR assay as previously published. ${ }^{27}$

Statistical analysis. Pairwise comparisons among patient groups were made using the Mann-Whitney test or Student's $t$-test. The level of significance was set at 0.05. Analysis was implemented using JMPv7.0 (Cary, NC).

\section{ACKNOWLEDGMENTS}

We thank UCDMC GI and J St Clinic staff, California HIV AIDS Research Program CH5-D-606, Dr Jerome Braun for statistical advice, Dr Michael George for paper review, and patients for their participation. Study support was provided by the National Institute of Health (NIH) R01 DK61297 and by NIH supplemental award AIO43274 and T32 AI-60555 for primary author.

\section{DISCLOSURE}

The authors declared no conflict of interest.

(c) 2008 Society for Mucosal Immunology

\section{REFERENCES}

1. Smith, P.D., Meng, G., Sellers, M.T., Rogers, T.S. \& Shaw, G.M. Biological parameters of HIV-1 infection in primary intestinal lymphocytes and macrophages. J. Leukoc. Biol. 68, 360-365 (2000).

2. George, M.D., Reay, E., Sankaran, S. \& Dandekar, S. Early antiretroviral therapy for simian immunodeficiency virus infection leads to mucosal CD4+ T-cell restoration and enhanced gene expression regulating mucosal repair and regeneration. J. Virol. 79, 2709-2719 (2005).

3. Guadalupe, M. et al. Severe CD4+ T-cell depletion in gut lymphoid tissue during primary human immunodeficiency virus type 1 infection and substantial delay in restoration following highly active antiretroviral therapy. J. Virol. 77, 11708-11717 (2003).

4. Mehandru, S. et al. Lack of Mucosal immune reconstitution during prolonged treatment of acute and early HIV-1 infection. PLOS Med. 3, e484 (2006).

5. Guadalupe, M. et al. Viral suppression and immune restoration in the gastrointestinal mucosa of human immunodeficiency virus type 1-infected patients initiating therapy during primary or chronic infection. J. Virol. 80, 8236-8247 (2006).

6. Brenchley, J.M. et al. CD4+ T cell depletion during all stages of HIV disease occurs predominantly in the gastrointestinal tract. J. Exp. Med. 200, 749-759 (2004).

7. Veazey, R.S. et al. Dynamics of CCR5 expression by CD4(+) T cells in lymphoid tissues during simian immunodeficiency virus infection. J. Virol. 74, 11001-11007 (2000).

8. Mattapallil, J.J. et al. Massive infection and loss of memory CD4+ T cells in multiple tissues during acute SIV infection. Nature 434, 1093-1097 (2005).

9. Picker, L.J. et al. Insufficient production and tissue delivery of CD4+ memory $T$ cells in rapidly progressive simian immunodeficiency virus infection. J. Exp. Med. 200, 1299-1314 (2004).

10. Li, Q. et al. Peak SIV replication in resting memory CD4+ T cells depletes gut lamina propria CD4+ T cells. Nature 434, 1148-1152 (2005).

11. Rodriguez, B. et al. Predictive value of plasma HIV RNA level on rate of CD4 T-cell decline in untreated HIV infection. JAMA 296, 1498-1506 (2006).

12. Brenchley, J.M. et al. Microbial translocation is a cause of systemic immune activation in chronic HIV infection. Nat. Med. 12, 1365-1371 (2006).

13. Giorgi, J.V. et al. Shorter survival in advanced human immunodeficiency virus type 1 infection is more closely associated with T lymphocyte activation than with plasma virus burden or virus chemokine coreceptor usage. J. Infect. Dis. 179, 859-870 (1999).

14. Kannanganat, S. et al. Human immunodeficiency virus type 1 controllers but not noncontrollers maintain CD4 T cells coexpressing three cytokines. J. Virol. 81, 12071-12076 (2007).

15. Feinberg, M.B. \& McLean, A.R. AIDS: decline and fall of immune surveillance? Curr. Biol. 7, R136-R140 (1997).

16. Harari, A., Petitpierre, S., Vallelian, F. \& Pantaleo, G. Skewed representation of functionally distinct populations of virus-specific CD4 T cells in HIV-1-infected subjects with progressive disease: changes after antiretroviral therapy. Blood 103, 966-972 (2004).

17. Munier, M.L. \& Kelleher, A.D. Acutely dysregulated, chronically disabled by the enemy within: T-cell responses to HIV-1 infection. Immunol. Cell Biol. 85, 6-15 (2007).

18. Aujla, S.J., Dubin, P.J. \& Kolls, J.K. Th17 cells and mucosal host defense. Semin. Immunol. 19, 377-382 (2007).

19. Cecchinato, V. et al. Altered balance between Th17 and Th1 cells at mucosal sites predicts AIDS progression in simian immunodeficiency virus-infected macaques. Nat. Mucosal Immunol. 1, 279-288 (2008).

20. Raffatellu, M. et al. Simian immunodeficiency virus-induced mucosal interleukin-17 deficiency promotes Salmonella dissemination from the gut. Nat. Med. 14, 421-428 (2008).

21. Poles, M.A. et al. Lack of decay of HIV-1 in gut-associated lymphoid tissue reservoirs in maximally suppressed individuals. AIDS (1999) 43 , 65-68 (2006)

22. Belmonte, L. et al. The intestinal mucosa as a reservoir of HIV-1 infection after successful HAART. AIDS (London) 21, 2106-2108 (2007).

23. Chun, T.W. et al. Persistence of HIV in gut-associated lymphoid tissue despite long-term antiretroviral therapy. J. Infect. Dis. 197, 714-720 (2008).

24. Strain, M.C. et al. Heterogeneous clearance rates of long-lived lymphocytes infected with HIV: intrinsic stability predicts lifelong persistence. Proc. Natl. Acad. Sci. USA 100, 4819-4824 (2003).

25. Chun, T.W. et al. Presence of an inducible HIV-1 latent reservoir during highly active antiretroviral therapy. Proc. Natl. Acad. Sci. USA 94, 13193-13197 (1997)

26. Chun, T.W. et al. HIV-infected individuals receiving effective antiviral therapy for extended periods of time continually replenish their viral reservoir. J. Clin. Invest. 115, 3250-3255 (2005).

27. Sankaran, S. et al. Rapid onset of intestinal epithelial barrier dysfunction in primary human immunodeficiency virus infection is driven by an imbalance between immune response and mucosal repair and regeneration. J. Virol. 82, 538-545 (2008).

28. Elrefaei, M. et al. Central memory CD4+ T-cell responses in chronic HIV infection are not restored by antiretroviral therapy. J. Immunol. 173, 2184-2189 (2004).

29. Lanzavecchia, A. \& Sallusto, F. Understanding the generation and function of memory T-cell subsets. Curr. Opin. Immunol. 17, 326-332 (2005).

30. Swiggard, W.J. et al. Human immunodeficiency virus type 1 can establish latent infection in resting $\mathrm{CD} 4+\mathrm{T}$ cells in the absence of activating stimuli. J. Virol. 79, 14179-14188 (2005).

31. Margolis, D.M. Confronting proviral HIV infection. Curr. HIVIAIDS Rep. 4, 60-64 (2007).

32. Lambotte, O. et al. Persistence of replication-competent HIV in both memory and naive CD4 T-cell subsets in patients on prolonged and effective HAART. AIDS (London) 16, 2151-2157 (2002).

33. Letvin, N.L. et al. Preserved CD4+ central memory T cells and survival in vaccinated SIV-challenged monkeys. Science (New York) 312, 15301533 (2006).

34. Verhoeven, D., Sankaran, S., Silvey, M. \& Dandekar, S. Antiviral therapy during primary SIV infection fails to prevent acute CD4+ T-cell loss in gut mucosa but enhances their rapid restoration through central memory T-cells. J. Virol. 82, 4016-4027 (2008).

35. Palmer, D.C. et al. Vaccine-stimulated, adoptively transferred CD8+ $T$ cells traffic indiscriminately and ubiquitously while mediating specific tumor destruction. J. Immunol. 173, 7209-7216 (2004).

36. Jansen, C.A. et al. Long-term highly active antiretroviral therapy in chronic HIV-1 infection: evidence for reconstitution of antiviral immunity. Antivir. Ther. 11, 105-116 (2006).

37. Correa, R. et al. Functional patterns of HIV-1-specific CD4 T-cell responses in children are influenced by the extent of virus suppression and exposure. AIDS (London) 21, 23-30 (2007). 


\section{ARTICLES}

38. Betts, M.R. et al. HIV nonprogressors preferentially maintain highly functional HIV-specific CD8+ T cells. Blood 107, 4781-4789 (2006).

39. Critchfield, J.W. et al. Multifunctional human immunodeficiency virus (HIV) gag-specific CD8(+) T-cell responses in rectal mucosa and peripheral blood mononuclear cells during chronic HIV type 1 infection. J. Virol. 81, 5460-5471 (2007).

40. Kannanganat, S., Ibegbu, C., Chennareddi, L., Robinson, H.L. \& Amara, R.R. Multiple-cytokine-producing antiviral CD4 T cells are functionally superior to single-cytokine-producing cells. J. Virol. 81, 8468-8476 (2007).

41. Aujla, S.J., Dubin, P.J. \& Kolls, J.K. Interleukin-17 in pulmonary host defense. Exp. Lung Res. 33, 507-518 (2007).
42. Kao, C.Y. et al. IL-17 markedly up-regulates beta-defensin-2 expression in human airway epithelium via JAK and NF-kappaB signaling pathways. J. Immunol. 173, 3482-3491 (2004).

43. Kosub, D.A. et al. Gamma/Delta T-cell functional responses differ after pathogenic human immunodeficiency virus and nonpathogenic simian immunodeficiency virus infections. J. Virol. 82, 1155-1165 (2008).

44. Creery, D. et al. Differential regulation of CXCR4 and CCR5 expression by interleukin (IL)-4 and IL-13 is associated with inhibition of chemotaxis and human immunodeficiency virus (HIV) type 1 replication but not HIV entry into human monocytes. Viral Immunol. 19, 409-423 (2006).

45. Papasavvas, E. et al. IL-13 acutely augments HIV-specific and recall responses from HIV-1-infected subjects in vitro by modulating monocytes. J. Immunol. 175, 5532-5540 (2005). 